\title{
Antibiogram of Isolated Organisms in Canine Pyometra
}

\author{
E. Niyas*, S. Reshma, G. S. Shravya, C. Jayakumar, R. H. Naveen Kumar, \\ N. Sarika and Anugraha Mercy Easaw \\ College of Veterinary and Animal Sciences, Mannuthy, Thrissur, Kerala, India-680651 \\ *Corresponding author
}

\section{A B S T R A C T}

\begin{tabular}{l} 
Ke y w o r d s \\
Canine, Pyometra, \\
Antibiogram, \\
Staphylococcus, \\
Escherichia coli, \\
Streptococcus and \\
Pseudomonas \\
\hline Article Info \\
$\begin{array}{l}\text { Accepted: } \\
\text { 14 May } 2020 \\
\text { Available Online: } \\
\text { 10 June } 2020\end{array}$ \\
\hline
\end{tabular}

\section{Introduction}

Pyometra, a life-threatening disease of intact adult bitches, is the accumulation of pus within the uterine lumen especially during or immediately following a period of progesterone dominance (Baithalu et al., 2010). The key feature is the hormonal imbalance which occurs during the luteal phase of oestrous cycle when the uterine immunity is low and the contaminating microorganisms dominate over the protective mechanisms of the female reproductive tract (Johnston et al., 2001).

The uterus of a dog normally does not harbour any microbes; usually its presence is due to the movement of organisms from the nonsterile vagina through the patent cervix during proestrus and oestrus, which cannot be cleared prior to the luteal phase (Watts et al., 1996). 
Survivability of the bacteria that enter into the uterus during oestrus depends on the uterine environment, virulence of the bacteria and immune status of the animal. During luteal phase, the progesterone- dominated uterus has diminished contractility and reduced infiltration of neutrophils into the uterine lumen. The organisms survive and multiply in the cystic fluid produced due to the cystic hyperplasia of the endometrium, a major predisposing factor of pyometra.

The toxins produced by the microbes cause systemic infection and leads to multiple organ dysfunctions (Kustritz, 2005). CEH-pyometra usually is a progressive disease of adult bitches that have undergone repeated oestrous cycling.

The overall mean age reported for bitches diagnosed with pyometra was 7.25 years, with a reported range of 4 months to 16 years (Johnston et al., 2001). Occurrence in young dogs may be due to treatment with oestrogens or progestins for estrus suppression or induction, contraception, or pregnancy termination.

Identification of the causative organism is of utmost importance while managing canine pyometra. The most common isolate recorded from canine pyometra was Escherichia coli which could be attributed to the fact that they are natural micro flora in the vaginal passage of bitches.

However, in the current context of antimicrobial resistance, it is ideal to conduct an antibiogram while choosing the antibiotic to be administered for therapy of canine pyometra (Smith et al., 2006). The purpose of this study was to evaluate the different phenotypic characteristics of organisms involved in canine pyometra, antibiogram of the isolated organisms and to extrapolate the findings to effectively manage the condition.

\section{Materials and Methods}

Ten female dogs, irrespective of their age and breed, suggestive of pyometra presented at University Veterinary Hospital, College of Veterinary And Animal Sciences, Mannuthy, Kerala formed the subject of the study. The confirmatory diagnosis of pyometra was based on the history, clinical findings, laboratory parameters and ultrasonographic observations. The animals exhibited clinical signs like vaginal discharge, polyuria, polydipsia, vomiting, inappetance, depression, systemic inflammatory response syndrome, dehydration, palpable enlarged uterus, pain on abdominal palpation, distended abdomen, fever, hypothermia and abnormal mucous membrane.

Samples were collected from the anterior vagina under aseptic condition using sterile swabs and were sent to the Department of Veterinary Microbiology for microbiological characterisation. The swabs were processed for conducting isolation of organisms and antibiotic sensitivity test. The contents in the sterile swab were spread in to a simple and enriched media and incubated at $37^{\circ} \mathrm{C}$ for period of 24 to $48 \mathrm{hrs}$.

Commercially available various ready to use dehydrated Medias (Hi-Media Laboratories Limited, Mumbai, India) were used for the preparation of culture media. The following media were utilized during the present study, Methylene blue agar, Brilliant-green phenolred lactose sucrose agar, Brain heart infusion agar, Mannitol salt agar, blood agar, Brilliant Green agar. Growth from isolated colonies was used for identification studies based on morphology, staining, cultural and biochemical characteristics. The discharge material was streaked over Mueller Hinton medium in such a way that a smooth, homogenous lawn culture was obtained. Plates were allowed to dry for 5 to 10 minutes at room temperature after inoculation. 
Standard disc of 10 antibiotics (Hi- media) were placed with the help of forceps and pressed gently to ensure full contact with the media. Plates were incubated at $37^{\circ} \mathrm{C}$ for 18 to $24 \mathrm{hrs}$. The inhibition zones of different antibiotics were recorded in $\mathrm{mm}$ and results were expressed in terms of sensitivity (S) and resistant (R). The sensitivity towards antibiotics was determined using the single disc diffusion method (Cruickshank et al., 1975). Zone of inhibition was measured using a Hi-media scale. Interpretation was made according to guidelines of clinical laboratory standards institute (CLSI, 2003) proposed for animal pathogens. Antibiotic discs used in the present study are as shown in Table-1.

\section{Results and Discussion}

\section{Diagnosis of pyometra}

Diagnosis was based on history, clinical findings, laboratory parameters and sonographic findings. Clinical signs exhibited by the animals are furnished in Table- 2 . The animals on transabdominal ultrasonography revealed presence of cystic hyperplasia of the endometrium and anechoic fluid sacculations in the uterus (Fig.2).

\section{Isolation of organism}

Based on the cultural, morphological and biochemical characterization, isolates from the selected cases were identified as Escherichia coli. Staphylococcus sps, Streptococcus sps, Pseudomonas sps and Bacillus sps. Major isolates included E. coli, Staphylococcus sps followed by Streptococcus sps and Pseudomonas sps (Table-3). Similar observations on the frequency wise incidence of organisms isolated from canine pyometra cases were also reported by Watts et al., (1996) wherein the isolated microbes in the order of frequency were Escherichia coli, Haemophilus species, $\alpha$-haemo-lytic streptococci, Corynebacterium species, Strept ococcus canis, Alcaligenes faecalis, Bacteroides species, Pasteurella species and Proteus mirabilis.

Similarly, Johnston et al., (2001) studied about the microorganisms present in canine pyometra and determined its antibiogram. The most commonly isolated organism included Escherichia coli, a member of the normal vaginal flora and additional bacteria isolates included Staphylococcus, Streptococcus, Pseudomonas, Proteus, Pasteurella etc which too corroborate to the present observations.

\section{Antibiotic sensitivity test}

Studies pertaining to the antibiogram pattern in canine pyometra illustrated that the sensitivity of isolates to antibiotics vary with the geographical location of the work and the type of the bacteria isolated.

In the present study, many of the isolates were found to be resistant to most of the commonly used antibiotics except a few, which highlights the significance of antimicrobial resistance. About ninety per cent of the cases were sensitive to ceftriaxone- tazobactam, followed by Ceftriaxone and amoxicillin (50\% and 40\%) respectively. The isolates were most resistant to Enrofloxacin, Ampicillin, Gentamicin (100\%) followed by Chloramphenicol, Cotrimoxazole and Oxytetracycline (90\%, $90 \%$ and 80\%) respectively.

However, since mixed infections were prevalent 100 per cent efficacy of a single antibiotic was not observed. Bassessar et al., (2013) during their study on antibiogram of bacterial species isolated from canine pyometra found that $E$. coli was most frequently associated with canine pyometra and aminoglycosides like Gentamicin and Fluoroquinolone like Enrofloxacin were the most effective antibiotics. 
Table.1 Antibiotics used for determination of the antibiogram of bacterial spp. isolated from canine pyometra

\begin{tabular}{|c|l|c|}
\hline Sl. No & \multicolumn{1}{|c|}{ Name of the Antibiotic disc } & Symbol \\
\hline $\mathbf{1}$ & Ampicillin & $\mathrm{A}$ \\
\hline $\mathbf{2}$ & Ceftriaxone-tazobactam & $\mathrm{Cf}-\mathrm{t}$ \\
\hline $\mathbf{3}$ & Enrofloxacin & $\mathrm{E}$ \\
\hline $\mathbf{4}$ & Amoxicillin & $\mathrm{Am}$ \\
\hline $\mathbf{5}$ & Ceftriaxone & $\mathrm{Cf}$ \\
\hline $\mathbf{6}$ & Chloramphenicol & $\mathrm{C}$ \\
\hline $\mathbf{7}$ & Tetracycline & $\mathrm{O}$ \\
\hline $\mathbf{8}$ & Gentamicin & $\mathrm{G}$ \\
\hline $\mathbf{9}$ & Cotrimoxazole & $\mathrm{E}$ \\
\hline $\mathbf{1 0}$ & Amoxicillin clav & $\mathrm{Am}-\mathrm{c}$ \\
\hline
\end{tabular}

Table. 2 Clinical signs exhibited by the animals with pyometra

\begin{tabular}{|c|c|c|}
\hline Sl.No & Case history and Clinical Signs & In Percentage $(\%)$ \\
\hline $\mathbf{1 .}$ & Vaginal discharge & 80 \\
\hline $\mathbf{2 .}$ & Lethargy / Depression & 100 \\
\hline $\mathbf{3 .}$ & Inappetance / Anorexia & 80 \\
\hline $\mathbf{4 .}$ & Polydipsia & 90 \\
\hline $\mathbf{5 .}$ & Polyuria & 70 \\
\hline $\mathbf{6 .}$ & Vomiting & 20 \\
\hline $\mathbf{7 .}$ & SIRS & 80 \\
\hline $\mathbf{8 .}$ & Abnormal mucous membrane & 30 \\
\hline $\mathbf{9 .}$ & Dehydration & 60 \\
\hline $\mathbf{1 0 .}$ & Palpable enlarged uterus & 40 \\
\hline $\mathbf{1 1 .}$ & Pain on abdominal palpation & 70 \\
\hline $\mathbf{1 2 .}$ & Distended abdomen & 40 \\
\hline $\mathbf{1 3 .}$ & Fever & 50 \\
\hline $\mathbf{1 4}$ & Hypothermia & 10 \\
\hline
\end{tabular}

Table.3 Organisms isolated from the samples collected

\begin{tabular}{|c|l|c|}
\hline SI No. & \multicolumn{1}{|c|}{ Bacterial sps } & In percentage $(\mathbf{\%})$ \\
\hline 1. & Escherichia coli & 90 \\
\hline 2. & Staphylococcus sps & 40 \\
\hline 3. & Streptococcus sps & 30 \\
\hline 4. & Pseudomonas sps & 20 \\
\hline 5. & Bacillus sps & 10 \\
\hline
\end{tabular}


Fig.1 Serosanginous discharge (Arrow head) noticed in an animal with open pyometra

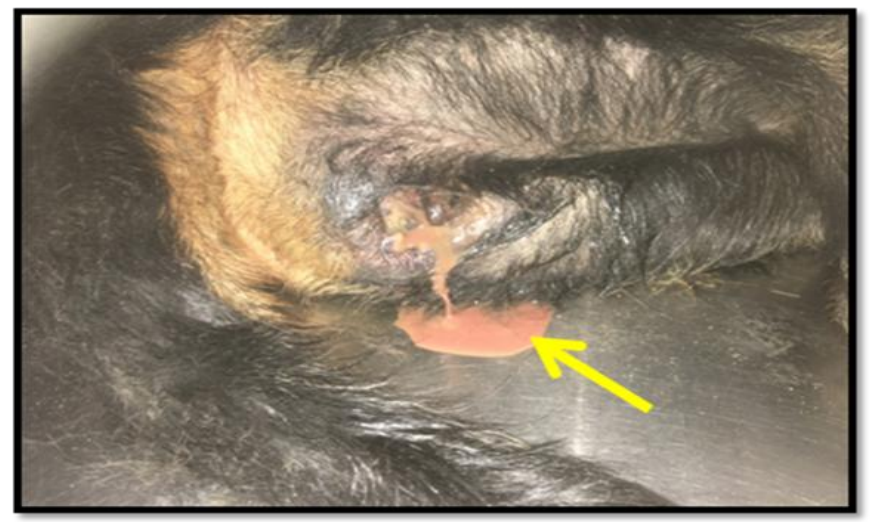

Fig.2 Transabdominal sonographic image of uterus with CEH- Pyometra complex; A: Anechoic fluid filled sacculations; Arrow head: cystic proliferation of endometrial glands

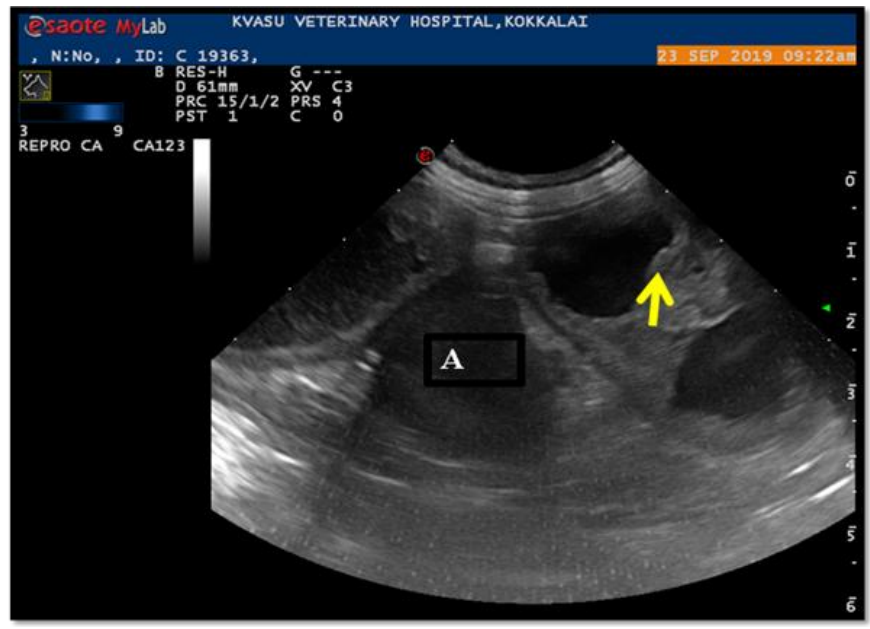

Mane et al., (2012) from their antibiotic invitro study, the antibiotic sensitivity pattern of major isolates showed significant variation in sensitivity and resistance, highest rate of resistance was against tetracycline $(80 \%)$ followed by Doxycycline (70\%), Trimethoprim (55\%), Ampicillin (50\%), Amoxicillin (40\%) and Ciprofloxacin (40\%) respectively.

Ovariohysterectomy is considered as the safest and most effective management since the source of infection is removed and recurrence is prevented. However, medical management can be an alternative in young and otherwise healthy breeding animals with open cervix and without other uterine or ovarian pathologies. Hence, an empirical antibiotic treatment is to be initiated and a culture and sensitivity of the sample should be carried out for the better outcome, especially with the ongoing threat of antimicrobial resistance. This is further evident from the results of the resistance of the organisms isolated in this study to most of the commonly used antibiotics.

Also, the favorable outcome in the dogs in this study that were initiated broad spectrum antibiotic treatment could be attributed to the modification of antibiotic to sensitive ones based on the results of initiated ABST. In 
addition, combined treatment with $\mathrm{P}_{4}$ receptor antagonist and rigorous supportive therapies and Treatment was initially started with broad spectrum antibiotic followed by antibiotic selected with ABST. Supplemented with P4 antagonist and supportive therapy and all the animals responded to treatment.

The study conducted on the phenotypic characterisation of microorganisms isolated from canine pyometra revealed the importance of identifying the bacterial agents causing canine pyometra. Also, the necessity of empiric antibiotic therapy to be followed with appropriate antibiotic based on susceptibility results for effective management of the disease along with supportive treatments is reinforced. In the present study the most common isolate was Escherichia coli and the most effective antibiotic was identified as CeftriaxoneTazobactam.

\section{Acknowledgement}

The authors are thankful to The Professor \& Head, department of Animal Reproduction Gynaecology and Obstetrics and The Dean, College of veterinary and animal sciences, Mannuthy, Kerala for allowing the facilities of the institution for conducting this research work.

\section{References}

Bassessar, V., Verma, Y. and Swamy, M.
(2013). Antibiogram of bacterial species isolated from canine pyometra. Veterinary World, 6. p.546.

Cruickshank, R., Dugie, J. P., Marimon, B. P. and Swain, R H. A. (1975) Medical Microbiology, 12thedn, Publ. Churchill Livingstone, New York; pp. 202-203.

Johnston, S.D., Kustritz, M.V.R. and Olson, P.N.S. (2001). Cystic endometrial hyperplaisa-pyometra complex. Canine and Feline Theriogenology, $1^{\text {st }}$ edn; pp.207-220.

Kumari Baithalu, R., Maharana, B.R., Mishra, C., Sarangi, L. and Samal, L. (2010). Canine pyometra. Veterinary world, 3 : p.340.

Kustritz, M. V. R. (2005) Cystic endometrial hyperplasia and pyometra. In: S.G. Ettinger and E.C. Feldman (ed.) Textbook of Veterinary Internal Medicine. 6thedn.,Pubu., Elsevier Saunders, St. Louis; pp. 1676-1680.

Mane, D.V., Patil, M.U. and Sawale, G.K. (2012). Antimicrobial Drug Resistance Pattern of Escherichia coli Isolated from Commercial Chickens. Indian Veterinary Journal, 89: p.12.

Smith, F. O. (2006) Canine pyometra. Theriogenology. 66: $610-612$

Watts, J.R., Wright, P.J. and Whithear, K.C. (1996). Uterine, cervical and vaginal microflora of the normal bitch throughout the reproductive cycle. Journal of small animal practice, 37: pp.54-60.

\section{How to cite this article:}

Niyas. E., S. Reshma, G. S. Shravya, C. Jayakumar, R. H. Naveen Kumar, N. Sarika and Anugraha Mercy Easaw. 2020. Antibiogram of Isolated Organisms in Canine Pyometra. Int.J.Curr.Microbiol.App.Sci. 9(06): 263-268. doi: https://doi.org/10.20546/ijcmas.2020.906.033 